The final publication is available at https://link.springer.com/chapter/10.1007/978-3-319-46152-6_4

\title{
The Serious Games Ecosystem: Interdisciplinary and Intercontextual Praxis
}

\author{
Phil Wilkinson ${ }^{1}$, Thomas Joseph Matthews ${ }^{2}$ \\ ${ }^{1}$ The Centre for Excellence in Media Practice, Bournemouth University, Bournemouth, UK \\ pwilkinson@bournemouth.ac.uk \\ ${ }^{2}$ The Centre for Digital Entertainment, Bournemouth University, Bournemouth, UK \\ tmatthews@bournemouth.ac.uk
}

\begin{abstract}
This chapter will situate academia in relation to serious games commercial production and contextual adoption, and vice-versa. As a researcher it is critical to recognize that academic research of serious games does not occur in a vacuum. Direct partnerships between universities and commercial organizations are increasingly common, as well as between research institutes and the contexts that their serious games are deployed in. Commercial production of serious games and their increased adoption in non-commercial contexts will influence academic research through emerging impact pathways and funding opportunities. Adding further complexity is the emergence of commercial organizations that undertake their own research, and research institutes that have in-house commercial arms. To conclude, we explore how these issues affect the individual researcher, and offer considerations for future academic and industry serious games projects.
\end{abstract}

Keywords: serious games $\cdot$ applied games $\cdot$ educational games $\cdot$ games for health · academia $\cdot$ commercial games $\cdot$ games for change $\cdot$ application domains $\cdot$ academic partnerships $\cdot$ research evaluation

\section{Introduction}

The intention of this chapter is for you - as a researcher - to reflect on your role in the serious games ecosystem. Although traditional models of abstract knowledge creation and dissemination apply in this instance, there is the opportunity to adopt different perspectives on research practice. It can be seen as enhancing knowledge creation capacity; the critical capture of knowledge; and the facilitation of praxis - the process by which research informs practice.

From the authors' experience, we - as researchers - often presume that we are the creators and distributors of knowledge. However, we often fail to take into account the importance of situated knowledge and practices surrounding the design, production, development, and indeed, application of serious games. 


\section{Chapter Overview}

This chapter will provide an overview and a snapshot of the current ecosystem. We will first attempt to establish the different positions - ontologies - that one as researcher might adopt. Building upon this we will negotiate our epistemological position; as before, with discussing the different contextual and inter-contextual practices of knowledge construction, it is necessary to consider the different conceptualisations of 'knowledge'. Additionally, we will re-articulate the definition of serious games that we will be using.

Narrative linearity will be imposed on the interconnected complexity of the serious games ecosystemthrough first discussing academic research practice. The commercial serious games sector will then be outlined, before moving onto the contextual adopters of serious games. There are of course numerous contexts [1], so for the purposes of detailing intercontextuality and interdisciplinarity this chapter will focus on both industrial (advertising, military, and corporate training) and non-commercial (social change, education, and healthcare) contexts. Explicit links will then be drawn with serious games commercialisation and exemplar studies research practice in these contexts.

Following the contextual overview, this chapter will discuss - with reference to specific instances of industry-academic partnerships - typical models and working practices used, suggested benefits, and emerging tensions. Equipped with this understanding, this chapter will finish with a reflective discussion of the serious games ecosystem and the implications for the individual, doctoral or early career researcher.

\section{Positioning in the Serious Games Academic Context}

A useful allegory for the evolution of serious games research is the general scientific method:

It began with a general hypothesis - games can be used for serious purposes: inherently evidenced in the introduction (or at least popularization) of the term 'serious games' itself [2]. This is followed by testing - how can this be proved: the first established focussed institute - Serious Games Institute Coventry in 2007 [3] - and first dedicated journal - EAI Endorsed Transactions on Serious Games in 2013 [4] - demonstrate the beginning of a structured pursuit of answers to this query. Finally, establishing theory for further testing - serious games are effective given a clear definition of 'effectiveness' and under certain conditions: a current research trend that will be explored further in this chapter.

Serious games research is now intersected with multiple fields of study. For the sake of creating an introductory text, these fields can be abstracted into academic interests chiefly concerned with one of four interlinked areas: conceptualisation, production, evaluation, and contextualisation. These areas can be further broken down. 


\subsection{Conceptualisation}

Conceptualisation - including definition modelling and sub-categorization is predominantly concerned with the framing of serious games.

Exploring conceptualisation closely illustrates the different epistemological positions that one can adopt as a researcher. For instance, game designers and researchers Mary Flanagan [5], James Paul Gee [6], and Ian Bogost [1], adopt a discursive, constructivist, approach to serious games conceptualis ation. They highlight the complexity of games as a socially-situated medium, and rely on large bodies of writing in their framing of serious games. Conversely, the work of researchers Jan-Paul van Staalduinen [7], Damien Djaouti [8], and Pauline Rooney [9] adopt an instrumentalist approach - seeking to distil the rhetoric and broader conceptualisations of serious games into replicable frameworks.

Like the work of Staalduinen [7], serious game frameworks often centre on the mapping of purpose driven concepts with game mechanics - such as rehabilitative criteria with games used in healthcare [10], therapeutic benefits of digital applications [11], theories of learning in games-based learning [12]. It is worth noting that in works specifically framing games-based learning, the term 'serious games' is often used rather narrowly: interchangeably with 'games-based learning' instead of an inclusive meta label $[7,8,12]$. The instrumentalist approach of developing readily deployable serious games is apparent in academic serious games production and evaluative research that focusses on replicability.

\subsection{Production}

Much like the conceptualization, serious games production is typically focussed on linking purpose-relevant theories with games development practice [10,12] . This is perhaps best illustrated through the development of the Ludens Modi Varietas model [13] through, again, the mapping of game elements with the Behaviour Change Support System (BCSS) to provide a theoretical basis for developing games for social change.

Whilst most serious games fields typically do this - affective computing will link emotionally representative game mechanics with the importance of emotionality in learning [14], and games for health will link the affordance of different interactive modalities in human computer interaction with frameworks for health goals [15,10], for example - this is not always the case. With games-based learning, a systematic review undertaken by Wu et al. [16] found a lack of design backed by established learningtheories.

This usage of domain or purpose specific theory linked to design practice, perhaps through necessity, is also apparent in the evaluation of serious games.

\subsection{Evaluation}

Serious games evaluation is currently a key focus in academia. A rise in serious game us age has led to multiple serious game categories, use-cases, and adopted domains [17]. Demonstrating the efficacy of games-based learning in particular is a deeply explored 
but contentious field in academia with multiple meta-analysis papers demonstrating effectiveness $[18,19,20]$. However, these studies are often plagued by difficulties in replicability [21], a lack of contextual ecological validity [22], and prescriptive measures of effectiveness $[23,24]$.

Games-based learning measurability is problematic due to a diversity of different measures used [23]. In this instance, the notion of measurability positions the researcher as a positivist, seeking to objectively prove a tangible outcome from a game's usage. Given this positivist epistemology, outcomes are frequently measured in terms of knowledge acquisition and increases in motivation [25]. Perhaps ironically, though there is an implicit agreement to prove effectiveness through measuring out comes, there is little agreement regarding what these measures should be or what methods should be used [22] [23]. In the field of games for social change, this fragmentation is also apparent in the narrow, sometimes ideologically driven, definitions of impact [24].

Of course this heterogeneity of effective measures and methods in broader serious games research is further confounded by multiple application domains and therefore domain-specific measures $[12,10,24]$. There are however developments of domain agnostic serious game evaluation methods - either systematically analysing game design [12], or through the application of user-centred validation techniques from other disciplines [26,27]. Again, these methods demonstrate an instrumentalist approach that seeks to provide consistent academic evaluative practices. Additionally, they attempt to move beyond positivistic definitions effectiveness towards a more interpretivist approach.

For instance, heuristic evaluation techniques are regularly applied to serious games evaluation, frequently drawing on pre-existing heuristics for evaluating games or technology systems such as playability and usability [28,29]. This approach of adapting heuristic evaluation techniques from related disciplines was also adopted in the development of a holistic approach to serious games evaluation as part of the Realising an Applied Gaming Ecosystem(RAGE) project [30].

Not only does the holistic approach put forward by Steiner et al. [30] situate learning outcomes with the pedagogic values of the institution, it also accounts for institutional experiences with serious game co-development and deployment. This holis tic contextualisation of serious games evaluation is illustrative of academic efforts to contextualise all aspects of serious games research.

\subsection{Contextualisation}

A key justification for the contextualisation of academic research - and indeed for the existence of this very chapter - is the necessity of understanding inter-contextual knowledge production. As already established, it is necessary to understand domainspecific intended outcomes of a serious game before said game's effectiveness can be evaluated $[10,19,24]$. Additionally, it is necessary to explore the adoption and deployment practices surrounding serious games [31,32,33,34] less we subscribe to notions of technological determinism, meaning the technology itself is the driving factor, not the practices surrounding it [35]. 


\subsection{Conclusion}

Returning to the concept of epistemology introduced at the beginning of this section, with the nature of knowledge, in the instance of academic research into serious games we see a mixture of positivist and interpretivist positions on knowledge creation that is then, frequently, instrumentalised. In contrast to this, and as the RAGE project appears to support, a question arises regarding where this knowledge originates. Given the industry interest in the development of serious games, and their different contextual usages, it is suggested that it is necessary for academia to position itself as a facilitator of knowledge creation, instead of just a creator of knowledge. As Eraut suggests:

"[Academia must] extend to its role from that of creator and transmitter of generalizable knowledge to that of 'enhancing knowledge creation capacities' of individuals and professional communities. This would involve recognising that much knowledge creation takes place outside the higher education system, but is nevertheless limited by the absence of support structures and the prevailing action-orientation of practical contexts." [36]

At this stage then it is worth considering the systems outside of higher education. To begin, we will explore more deeply the industrial, production-orientated, practices surrounding the development of serious games. These practices will be interlinked with the research areas already discussed. However, before looking deeply into the minutia of the serious games industry it is necessary to unpack what we mean by 'industry', understand its size and scale, and have an awareness of the types of organisation that can be said to constitute this industry.

\section{Academic Industrial Serious Games Partnerships}

Since the late $19^{\text {th }}$ century, the university as educational institute has undergone three revolutions of purpose. This first revolution was an expansion of their remit from the capture and dissemination of knowledge, to active production of new knowledge through research [37].

According to Etzkowitz [38], a second revolution of academia has resulted in increased academic-industrial partnerships as governmental science policy agendas attempt to translate research findings into economic development [39]. This, of course, has direct corollaries for the serious games ecosystems as we witness an increase in the number and sophistication of academic-industrial partnerships. This increase in partnerships is perhaps best exemplified by the rise of academic-industrial networks such as the Games and Learning Alliance [40], the Serious Games Institute Community [41] , or the Serious Games Society [42].

Perhaps best representing the third academic revolution [39] is the Realising an Applied Games Ecosystem [30]. Among other goals, RAGE aims to develop a "social space that connects research, gaming industries, intermediaries, education providers, policy makers and end-users" and a central depository for the 'assets' used in the production of serious games - in this instance referred to as applied games. Therefore, RAGE embodies an academic purpose to create economic development through engagement with industrial partners. In addition to this direct partnership with industry to 
create economic value, there is an entrepreneurial spirit underlying the third revolution of academic purpose [43].

\subsection{Entrepreneurialism}

As universities engage with industrial partners in a policy driven culture of prioritizing economic development they develop their capacity for generating economic value - through translating research findings into intellectual property or products that are monetized. It follows then, that universities are able to have direct economic agency through a spirit of entrepreneurialism, rather than indirectly through partnerships with industry [43]. This notion is apparent in the RAGE project, with the development and dissemination of "a business model and launch plan for exploiting RAGE results beyond project's duration" as one of the projects deliverables [44].

As university funding is squeezed through increased student populations and the present shadow of global economic downturn, universities themselves have increasing interest in offering commercial service. Sara de Freitas, through her work as founder of the Serious Games Institute [3] - a research centre that offers applied research consultancy and bespoke serious games design - developed the Innovation Diffusion Model (IDM) [45].

It is the intention that this model for academic-industrial partnerships will afford universities direct financial reward for their research - through commercial income, and knowledge exchange targeted funding - whilst industry benefits from new intellectual property and access to a highly-skilled workforce [45]. This commercialised approach to research, has also been expanded in the form of Serious Games International [46] - an international, commercial spin-out.

This notion of entrepreneurialis $m$ in academic research centres - resulting from industrial partnerships; research centres offering commercial services; and the emergence of spin-out commercial organisations - exemplifies a challenge when discussing the serious games industry. That is, this industry is a heterogeneous collection of research, commercial, not-for-profit, individual practitioners and governmental organisations often with blurred lines of demarcation. Therefore, before we begin to make generalised sweeping statements about serious games industry's experience with serious games conceptualisation, production, evaluation, and contextualisation - it is worth considering this heterogeneity.

\subsection{Heterogeneity}

Typically, a serious game production company will either develop serious games on a consultancy bas is for specific project (Business to Business), or as products for release in the serious games marketplace (Business to Consumer). PlayGen [47] for instance is a UK-based studio that creates serious games bespoke for client needs, such as raising awareness of flood risks [48], or promoting prosocial behaviours and criticality of violent extremism [49]. In addition, international consultancy firms not typically associated with games development, such as IBM [50] or Deloitte [51], offer comparable services. 
For games-based learning in particular, the Business to Consumer business model is common. In 2014 games-based learning industry was reportedly worth $\$ 1.8$ billion with $\$ 1.4$ billion of this coming from consumer purchases as opposed to institutional, governmental, or commercial purchasing [52]. It is difficult to ascertain the total worth of entire serious games market - again, due to difficulties in categorization [53]: for example, Interpret valued the entire serious games market at $\$ 10$ billion in 2012 [53], whereas Ambient Insight valued the entire market at $\$ 4$ billion for the same year [54], moving up to $\$ 6$ billion in 2014 [52]; finally, Marketsandmarkets estimated that the serious games market will only be valued at $\$ 5$ billion by 2020 [55]. Typically, these figures are linked to corporate, health, military training, institutional, and/or consu mer education products, but the estimations fluctuated depending on the definition of serious games used, reflecting the existing epistemological issues discussed earlier in this chapter.

Not all of the serious games industry is framed around commercial gain, however. Games of Change is a non-for-profit organisation that "facilitates the creation and distribution of social impact games that serve as critical tools in humanitarian and educational efforts" [56]. It has created a network of organisations invested in the development or adoption of social impact games - also known as 'impact games' [24] or 'games for social change' [57]. In addition, they host competitions for game ideas designed around specific topics such as 'safe sex' [58] or 'nuclear weapons' [59]. This activist approach to developing serious games is also typical of other charitable, international, and inter-governmental organisations $[60,61,62]$.

Paralleling this organisational development of games for social change, coinciding with the rise in popularity of projects not funded by traditional publishing sources - or 'indie games' - in entertainment games production, is the independent creation of 'social awareness' games such as Depression Quest [63] or That Dragon, Cancer [64]. It is worth noting that these 'indie games' do not typically analyse the social impact of their content and messages in the same fashion that consultancies or organisations do, and instead often originate from personal artistic messages.

From the individual socially motivated developer, to the studio developing corporate training games, and finally the multinational governmental organisation furthering a political agenda, all can be said to be a part of the serious games industry and broader ecosystem.

\subsection{Conceptual Blurriness}

The muddiness of conceptualisations and definition apparent in academic discussions of serious games is reflected by similar problems in the industry. As previously mentioned, 'games for social change' are also categorized as 'impact games', 'games for change', 'purposeful games', or 'transformational games' depending on your perspective and field. With this instance of serious games specifically, there is further blurriness as with the notion that 'transformational games' can be applied to general entertainment games as well [65].

This conceptualblurrines s has created obstacles for serious game developers seeking funding calls, as the descriptions of such calls impress a sense of consensus on topics 
that require further debate. As one game developer put it "D'you know what my biggest obstacle is? Just knowing what a 'game for change' is and knowing if the thing I'm making fits the criteria." [24]. Of course there are knock-on effects of this fragmentation for production and evaluation practices. In an interview, Jessie Schell - founder of serious games company Schell Games - on the subject of serious games described a problem of perception:

"[T]here's often a kind of inauthenticity that surrounds these kinds of games. They make promises about taking this boring thing and making it fun, but if they fail, you just go, 'This really is bad.... Teaching is really hard. Making an entertaining game is really hard. And now we're proposing that we're going to do both of them simultaneously" [65].

Schell raises two relevant points here. Firstly, the difficulty of melding complex interdisciplinary theories and practices, and, secondly, a notion of inauthenticity, or a lack of rigour, in the industrial production of serious games. This lack of rigour is supported by a research report commissioned by Games for Change [24]. According to this report, game developers do not have the development time available for rigorous pre-production research integrated design, due to limited resources and a necessity to prioritise income-producing activities. Perhaps due to this time constraint, a report produced through the RAGE project suggests surveyed games developers expressed a desire for pedagogic strategies [66].

Interestingly, the same RAGE report that highlights a desire for pedagogic strategy resources from developers also seems to suggest a superficial understanding of pedagogic strategies on the part of these developers [66]. This lack of deep integration of theories of learning with games production is not isolated to industry however. According to $\mathrm{Wu}$ et al's [16] meta-analysis, a majority of games-based learning projects do not explicitly align with the one of the four key learning theory paradigms.

\subsection{Learning Theories}

MeTycoon [67] provides an example of the use of learning theories in the production of digital learning games. The game uses the concept of variable interval reinforcement as outlined in the behaviourist theory of learning established by B.F. Skinner [68]. However, although this notion of reward schedules is critical in behaviourist learning theory, it is deployed primarily as a means of maintaining player engagement, rather than fostering learning [69]. Additionally, this example demonstrates the challenge of intercontextual praxis, marrying academic theory and professional practice - with interdisciplinarity adding further difficulty. This is shown with the choice of MeTycoon's learning theory being behaviourism, despite the fact that behaviourism has mostly fallen out of favour - due its reductionist conception of learning - in contemporary pedagogic practices, replaced instead by cognitivism and a rising interest in constructivism (see chapter on games-based learning).

It is of course facetious to make sweeping statements regarding approaches to the development key for serious games. Even the industry-led reports referenced in this section only provide a limited snapshot. For instance, the romantic image of a games development studio as a perennially playful environment with free-flowing creative 
process not constrained by traditional industry project management or business practices is readily challenged in a study undertaken by the British Educational Communications and Technology Agency [70]. Instead, games developers will often utilize a systematic, iterative rapid prototyping, agile development approach.

\subsection{Conclusion}

Therefore, it is not the intention of this section to critically appraise the serious games industry, but instead to equip the reader with a criticality that can be used when engaging with the broader serious games ecosystem. For instance, there are suggestions that serious games developers over-represent the benefits of their games and lack robust evaluation practices [24,71]. As suggested by an Impact report in 2015:

"If the lack of evaluated games is any indication, a common scenario is to focus on creating the game and worry about evaluation once it is done (if at all)" [24]

It is easy to reach the conclusion that games developers do not wish to invest in evaluating their game as it may prove its ineffectiveness [71]. However, going back to Eraut's notion of industrial action-orientation [36], for commercial organisations it may not be a lack of willingness but a lack of capacity. A robust evaluation of a serious game's effectiveness requires a non-trivial investment of resources. In addition to this challenge of limited resources in organisations that are profit-driven; there is also the challenge in finding commercially appropriate evaluation methods.

Reflecting the challenges in academic approaches to evaluation, there is a suggestion that commercial organisations experience a similar debate regarding how to prove serious games' effectiveness. For instance, a report, commis sioned by Games for Change, suggests that there is a narrow definition of 'impact' - a conception of effectiveness relying instead on the superficial use of evaluation methods [24]. It is perhaps for these reasons - both the narrow definition of 'impact' and lack of capacity for evaluation that games developers express a desire for easily implemented evaluation approaches [66].

Of course evaluation approaches used in commercial settings - just as in academia - will be reflective of the outcomes desired by the context the serious games are deployed in. In addition, production practices such as user-centred design, or agile development, prioritise the consistent involvement of the end-user and stakeholders. Furthermore, the conceptualis ations of games will also be contextually focused.For instance, games-based learning games used in corporate training sectors may elevate their return on investment [72], whereas in educational settings they may discuss their alignment with standardised national curriculums [73]. It is therefore necessary to consider the context adopting serious games in more detail.

\section{Contextual Application Domains for Serious Games}

A consistent theme of the academic and industry practice discussed in this chapter is the need for situating such practice in context. Additionally, from the perspective of academic practice specifically, increasingly the onus is on demonstrating the 'impact' 
of research in terms of influencing discourse, behaviours, or practice outside of academia [74] . Additionally, serious games are often classified in relation to their adopted contexts or market areas [75]. This section will therefore discuss the adoption of serious games in different contexts - specifically advertising, social change, military, corporate training, education, and healthcare.

We will discuss these contexts as they are the largest contemporary adopters of serious games [52]. Additionally, these contexts will demonstrate the pre-eminent motivations behind the use of serious games. However, a problem of classification occurs as with the term 'serious games' itself - as the classifications used are broad and refer to intertwined contexts. For instance, the educational contexts for the use of serious games - in this instance - refer to both formal and informal education.

As we will see, motivations for the use of serious games in these contexts predominantly rely on the 'holding power' of games [76] - also referred to as 'flow' [77] or 'engagement' [78] - to achieve their aims. The topic of 'engagement' is relevant here as it, again, highlights the difficulty of modelling serious games terms as well as tensions inherent in inter-contextual practices. Defining 'engagement' in serious games research has become a key focus for academics, as it forms a core argument for the utilization of games over other interactive mediums, and therefore will inform design [79] and the metrics used to determine effectiveness [80,79,81]. However, the term 'engagement' has set meaning in educational contexts, so the meaning of this term does blur within the games-based learning field. This kind of engagement is not just applied to educational serious games however.

\subsection{Advertising}

Advergames - advertising games - seek to exploit the engaging nature of games to for the purposes of advertising [82]. This includes both the use in-game advertising in entertainment games - such as virtual billboards or branded in-game items [83] - and the bespoke development of games designed to engage players with a commercial brand [82]. For instance, The Scarecrow [84] is a game designed by US fast-food company Chipotle to promote the values of the company [85]. Of course, this has raised ethical considerations as these predominantly web-based games are accessible by, and frequently designed for, children. Therefore, in the case of fast-food advertisements there are concerns regarding this form of brand engagement [86].

\subsection{Social Change}

The 'advergames' approach to brand engagement through digital games is reflected by the production of games for social change. These games, often produced by commercial, industry studios on behalf of charitable organisations, seek to engage the users with social issues for the purposes of raising awareness, challenging beliefs, or changing behaviours [75].

An example of a more direct approach, Freerice [87], is an ad-supported, free-toplay 'game' supported by the World Health Organisation that donates 10 grains of rice 
for every correct answer from the player in a simple vocabulary quiz. Freerice's approach to generating donations through crowdsourced player engagement is reflected by a broader movement to crowdsource donations through in-game purchases. Furthermore, Freerice is evidence of blurring between social change and educational with its language learning focus [88].

Though not strictly related to serious games, just as advertisers are able to purchase advertising space in entertainment games, charitable contributions can be made through purchasing virtual products in-game [89,90]. Similarly, there are some serious game projects which crowdsource beneficial data analys is through playfulmechanics: Citizen Science [91], for the analysis of cancer cells data, and Foldit [92], for the analysis of protein folding, are two such examples.

Games for social change and advergames both seek to exploit the engagement potential of games. Such games that are designed to raise awareness, challenge beliefs, change behaviours [75], or create direct, crowdsourced, contributions to a cause [91,92], along with advergames that seek to promote a brand or commercial values, rely on player engagement.

\subsection{Military}

Another application promoting values through player engagement - not commercial or charitable values but military values - is evidenced with America's Army, a serious games published by the United States Armed Forces which aims to use "computer game technology to provide the public a virtual Soldier experience that was engaging, informative and entertaining." [93]

The popularity of America's Army, now a platform of media tools used for recruitment and virtual training [94], has given rise to much critical discussion regarding its ethical deployment. It is of course a controversial topic with those arguing the game is a rather disingenuous piece of propaganda [95], that provided an insincere sense of realism [96], with additional criticisms over its use in schools [97]. However, the game itself has additionally received much praise for its changing of perceptions in 16 to 24 year olds, with studies suggesting that $29 \%$ of this group saw the US Army more positively as a result [98].

From these examples of advergames and games for social change we can see the notion of engagement framed both as a creation of new engagement opportunity, and of providing longer term engagement. In addition, this usage of engagement, frequently framed as 'motivational capacity' [99] or 'holding power' [100], is a key argument for their usage for corporate training and - as in the case of America's Army - recruitment.

\subsection{Corporate Training}

In corporate training there are two adjacent methods - simulation-based learning, and gamification. Simulation-based learning refers to the provision of a virtual learning environment that is able to be explored. Again, this definition is also not sacrosanct. With this definition in mind, we can then differentiate games -based learning from simulation- 
based learning through the presence of game mechanics. Furthermore, gamification refers to the application of game mechanics and tropes - such as leaderboards, goals, or points - to, in the context of corporate training, business processes.

To further complicate matters there is also a rising use of game mechanics within simulation-based learning. It is therefore difficult to paint a clear picture of how serious games are being used, and to what degree they have been adopted [34]. In addition, it is difficult to gather empirical evidence regarding their effectiveness in commercial contexts [101]. Continuing the pattern of applying contextually relevant assessments of effectiveness, there are, however, examples of applying corporate training evaluation frameworks. For instance, Johnson and Wu [102], O’Neil et al. [103], and MartínezDurá et al. [104] have all applied the Kirkpatrick [105] levels of learning effectiveness to assessing serious games.

Given the complexity of defining serious games in a corporate training context, stratifying these serious games in terms of learning needs can help our understanding [106]. For instance, the training needs of a commercial organisation may range from the development of generalizable prosocial skills, often referred to as soft skills - such as communication, team-work, or empathy - to sector specific knowledge of compliance regulations, physical layouts of working environments, or role-orientated continued professional development. As a conceptual mapping of these needs, we can adopt Bloom's taxonomy.

Bloom's taxonomy [107] demarcates learning into three domains - cognitive, psychomotor, and affective. Therefore, in the instance of serious games in corporate training, cognitive will refer to acquisition of knowledge and development of mental skills - such as compliance training, and the development of marketing professionals. It is of course worth noting that this application of Bloom's taxonomy to serious games modelling is not unique to corporate contexts $[108,12]$ and is frequently applied to games used in education.

\subsection{Education}

As with other applications of serious games, as discussed in this chapter, the difficulty in evaluating the effectiveness of serious games re-emerges for the training and learning applications (for a more detailed discussion of the theoretical underpinning behind games in education see the chapter on games-based learning in this volume). To evaluate the effectiveness of games designed for training or learning, often context-specific measures or frameworks will be used. For instance, in the case of serious games for corporate training, the game may be evaluated in terms of a return on investment, as well as in relation to key performance indicators [72]. For games used in state-education settings, they may be aligned with curriculum standards [73].

Games-based learning's class room adoption is often justified through perceived motivational ability - of 1600 UK primary and secondary schoolteachers surveyed, $60 \%$ would use games in their lessons for this reason [109]. Furthermore, as $99 \%$ of 8- to 15-year-olds have played some form of video game in the last six months [110] - combined with a prolific notion of the 'digital generation' [111] - there is the argument that the education of this age group must be digitally supported; including the use of digital 
games [112]. Although the efficacy of games-based learning techniques has been empirically proven - when compared with traditional instruction methods, under given conditions, for certain subjects $[113,25]$ - there are still challenges to their adoption.

From the pers pective of professional praxis, the biggest challenge is perhaps educators changing role - moving from leader to facilitator [114]. Questions are also raised regarding game-related expertise. In 2006, a $72 \%$ majority of teachers (at both primary and secondary level) surveyed by Futurelab state they never play video games in their spare time, with only $36 \%$ of primary teachers and $27 \%$ of secondary teachers having used games in the classroom in the past [115].

Combined with this is the expectation from teachers that their pupils are gaming experts [116]. In some cases, this has created a sense of shared expertise, as pupils show teachers how to play games and teachers show pupils how to analyse their content in media subjects [117]. Furthermore, lack of supporting materials, availability of resources, and the inflexibility of the curriculum are cited as barriers to adoption [118].

Teachers citing of a lack of supporting materials is indicative of the current appro ach in, at least, the industry's development of serious games. They are often developed to be engaged with as independent activities, relying on behaviouristic notions of learning, without taking into account the role or the learner's peers or teachers. However, in the case of educationalgame platforms like MyMaths [119] and Lexia [120], there is additional functionality for teachers, like measuring and tracking the engagement and performance of their learners.

Acquiring those metrics relevant to the educational context, and meaningfully presenting them to educators, is an emerging topic of research [121] - somewhat reflecting broader movements in education towards data-driven, or 'big-data' practices. In addition to this is development of educational games that are not only designed to educate but also to assess learner's progress. Moreover, there are recent efforts in educational game development to account of the changing emotional states of the learners and how this relates to their engagement with learning activities [14]. This accounting for the role of data-capture, continuous assessment (or performance observation), and emotional acuity indicates an awareness of the educational context that serious games are adopted in. There is however, scope for this to be expanded.

Research is emerging from the Joan Ganz Cooney centre that explores the notion of joint media engagement: the design of apps for co-viewing by children and parents $[122,123]$. In this case, reflecting the Sesame Workshop's broader purpose of at-home education through media [124], the res earch refers to using co-engagement as a strategy for learning at home. However, given the rise of digital media resulting in a shift from teachers as leaders to facilitators of learning, drawing on social theories of learning such as Vygotksy's More Knowledgeable Other [125], there are still ways in which serious games design can be aligned with pedagogic practice to be designed as such that teachers or peers can play an actual, often supporting, role.

As previously discussed, the marrying of theories of learning with serious games design principles is often dependent on the subject matter of the game. For instance, the practice of mental mathematical skills is often supported through a behaviourist game 
design - sometimes referred to as drill-and-practice learning [126]. Whereas constructivism suggest learners actively construct knowledge as they make sense of their experiences [127]: more fitting to general problem solving skills.

This notion of constructivism in serious games has been both theoretically, and pedagogically, developed by the work of constructionist Seymour Papert. In his work on the pedagogic potential of project-based production he closely explored the role of digital games:

"I have found that when they get the support and have access to suitable software systems, children's enthusiasmfor playing games easily gives rise to an enthusiasmfor making them, and this in turn leads to more sophisticated thinking." [128]

Furthermore, Kafai - proponent of games making as a learning approach and former student of Papert - suggested that "videogames, because of their prevalence in youth culture, present a particularly promising application for creative production." [129]. In the book Connected Code [130], early learner-led serious games development pioneer Yasmin Kafai discusses her experience of using the education-driven programming language LOGO - created by Papert [131] - in a games development environment. Over the course of a year, based in a school, students used the LOGO language to create mathematical educational games for other students to use. This use of game authoring tools for developing serious games for traditional curriculum subjects - especially mathematics - is apparent today [132,133,134,135].

In addition, there are frequently commercially backed ventures that attempt to use digital games development as a means of developing digital literacy skills. Kodu [136] - Microsoft's visual game programming environment - is designed to "teach creativity, problem solving, storytelling, as well as programming" [136] through game development software that is, in itself, 'game-like'. Additionally, Microsoft also runs the software development competition 'Imagine Cup' [137], in which a recurring category involves students aged 6-18 developing games around a common theme and/or accessible development tool. Additionally, the Joan Ganz Cooney centre runs 'The Video Game Challenge' [138] yearly in which high-school aged students are invited to create and submit games designed to teach a Science, Technology, Engineering, or Maths (STEM) subject.

Just as there is confusion regarding the role of serious games in corporate training settings, due to the prevalence of gamification, simulation-based learning and e-learning solutions, there is also the same conceptual confusion in education. To discuss the role of games in education invites interdisciplinary perspectives on: the purposing of commercially available off-the-shelf games; the design, production, and development of games - both serious and non-serious - as a constructionist pedagogy; and the adoption and utilization of educational serious games. However, at the centre of this complexity is the purposing of digital games for learning. 


\subsection{Healthcare}

As will become apparent there is a difficulty in consistently framing the discussion of serious games in healthcare. Attempting to provide a broader review of the modelling, design, development, and evaluation of serious games in healthcare is challenging due to the multitude of purposes for these games.

According to Tom Baranowski et al. [139] - editor of the newly-emerging Journal for Health Games - there are currently 4 classifiable types of health games. Games for health to increase knowledge for health and wellbeing, games for health to explicitly alter behaviours, games for health to subversively promote behaviour change through game play, and games for health that influence negative health precursors. Again these suggested types are related to the purpose of the game itself, and we can see a degree of overlap with serious game definitions from other context.

As with other domains, the primary use of serious games in healthcare revolves around training and learning - or games that increase knowledge. However, there are different motivations for their adoption. Serious games have been developed for multiple aspects of healthcare. For surgery [140] there are serious games for training in laparoscopic techniques [141], knee-replacements [142,143], and blood management [144]. In addition, there are examples of serious games used for the training of nurses to manage pain [145].

Virtual Pain Manager [145], was designed as an opportunity for nursing staff to gain practical understanding of managing a patient's pain overtime. This game is intended to be used as a training tool following instruction in pain management theory. Similar to this, Florence [146] is a serious game designed to train nurses in the necessary practice surrounding three challenging areas - blood transfusion, fire safety, and hazardous materials handling. These serious games demonstrate a key motivation for the adoption of serious games in healthcare: they allow for practice and training given in simulations of real-world conditions in otherwise dangerous areas.

A recent review of the current state of games in healthcare suggested that they are more common place in some areas than others - one of these areas was basic first aid training [147]. In the domain of first aid-training there are again examples, like Virtual Pain Manager and Florence, that are designed to give training for situations difficult to replicate in the real-world. For instance, Code-Orange [148] is a serious game designed for medical staff and first-responders to gain experience in the management of crisis following the use of a weapon of mass destruction. Following this training for health-care professionals, there of course multiple examples of serious games designed for the patient education.

Given the requirement for consistent adherence to insulin injections there has been great interest in using video games for diabetes self-management, especially in the case of Type-1 diabetes [149]. With diabetes there are multiple approaches adopted with serious games. For instance, The Diabetic Dog [150] is a game in which the player must care for a pet dog with diabetes, which includes the management of insulin levels. This use of serious games to educate the player in diabetes self-management can even be traced back to $1997[151,152]$. 
Didget [153] is a physical blood glucose reader that interfaces directly with a Nintendo DS handheld console and game associated with it. Through checking and maintaining acceptable glucose levels regularly, they are rewarded with in-game items. Interestingly, this is perhaps an example of both a serious game and of gamification, as it has layered a reward schedule over a real-world process, but such rewards are virtual in-game items.

In any case, this game serves as an illustration of the broader purpose behind these health training games designed for patients. That is, they are designed to change behaviours. As suggested by seminal social learning theorist Albert Bandura [154], and subsequently summarised by Debbie Thompson: "Knowledge and skill provide the foundation for behavior change" [155].

This approach is not specific to the development of health games for diabetes. Remission [156] is a serious game ostensibly designed to inform adolescents about their ongoing cancer treatments. From the use of this game they found patients were more knowledgeable about their treatment, more likely to adhere to their treatment regime, and exhibit a more positive outlook than pre-intervention [156].

It has been suggested that empowerment through playing games, prior to surgery, can reduce physiological reactions associated with fear and anxiety, and enhance resilience - therefore reducing post-recovery time [157]. Taking this a step further, there are examples of serious games designed as clinical tools in treating underlying psychological conditions. SPARX [158] is a 3D adventure game that has Cognitive Behavioural Therapy embedded in its gameplay. It has been demonstrated that this approach is as effective - in the short term - as compared to face-to-face counselling [158], although long term data has yet to be collected. Relating to this, there is scepticism towards the usage of such games as/in interventions [159].

At this point we again witness the diffusion of serious games definitions and categories. Games for health that are designed to increase knowledge can also have the aim of changing behaviours through this increase in knowledge. This overlap of purpose can also be applied to the typical approach of games for social change. That is, behaviour change is achieved through educating the player - in the case of health games - of good health self-management habits. Following the focussed application of serious games for behaviour change in specific groups, this has also been applied more broadly to target the general public.

Riccardi et al. [147] suggests that, as with the justification for their commercial adoption, serious games can be more cost effective - than traditional approaches - for preventative healthcare. Typically, these games focus on the promotion of healthy lifestyles and have been proven - again, in the short term - to be effective in encouraging healthy behaviours in players [151]. So rather than providing training or education for those already living with medial is sues, these serious games adopt a preventative stance to curb medical issues before they arise. As with the application of serious games generally, there is a particular focus on designing health games for children [139].

Yummy Tricks [160] and Squire's Quest [161] are both designed to promote healthy diets in young children through centring mechanical metanarratives around ideal culinary behaviours. Whilst Yummy Tricks and Squire's Quest have a comparable purpose, with a similar target group, they adopt different challenges. Yummy Tricks was offered 
as a classroom-based activity whereas Squire's Quest was made available online for individual play. This illustrates a dilemma on the part of the serious game developer: capturing children's attention when their activities are already controlled, for instance at school, is easier than capturing their attention at home when they have more freedom and indeed choice in which media they consume [162,163].

Perhaps most clearly demonstrating the overlapping contextual domains of serious games - and perhaps the futility of this chapter's attempt to demarcate them - is the development of serious games for change focussing on health. Not necessarily developed for use by healthcare professionals, or for use in healthcare contexts, these games attempt to address a societal problem relating to healthcare. For instance, both Depression Quest [63] and Elude [164] are games focussed on representing the experience of living with depression. Elude, specifically, was designed for family and friends of a person living with depression to gain more understanding, knowledge, and empathy [164].

Reflecting educational practices in games adoption, healthcare professionals are exploring the capacity of non-serious games to support mental health, rehabilitation, and pre-empt cognitive degradation. In one such example, there was a randomised control trial conducted in which casual video games had been demonstrated to have a positive impact on depression and anxiety $[165,166]$. Again, citing the motivational potential of video games, there is evidence demonstrating game-based interventions can be used as a means of maintaining patient engagement with effective rehabilitative practices [167]. Additionally, this 'clinical' application of casualor typical games allow patients to replicate these practices at home $[168,169]$, and demonstrate the capacity of existing nonserious games for health to include the preferential behaviours as part of the game-play, fulfilling the same purpose as serious games for health.

Paralleling the interest in developing game-based health interventions and games designed to change behaviours in children, there is increasing interest in the application of digital games for the elderly [170]. A systematic review found several positive health benefits emerging from this area of commercial, off-the-shelf games, including mental, physical, and social health benefits [171]. Focussing on the application of digital games for persons living with dementia, a review revealed that the majority of games used are, again, commercial games [172]. Despite this, serious games - as opposed to off-theshelf games - have been identified as a potential clinical tool for dementia [173].

When reviewing the adoption of serious games vs non-serious games in healthcare contexts, we can see a general trend of the latter outnumbering the former. Where the purpose is to enhance knowledge or promote a specific behaviour, games are predominantly 'serious' - perhaps as their content is required or recommended to be specific and precise, not muddied by entertainment or narrative goals. Conversely, where the purpose is to engage the player in the desired behaviour during gameplay, or where the game is designed to address influence health precursors, 'non-serious' games are more popular. Specifically looking at physical rehabilitation, the proliferation of exergames and associated, low-cost, feedback technologies makes their application appropriate $[15,174,175]$.

Regardless of the purpose behind the adoption of serious or indeed non-serious games, there is a stringent necessity in healthcare for robust evaluation processes. This 
is perhaps a key difference between the adoption of serious games in other contexts and in healthcare. For instance, there are several randomised control trials attempting to prove the efficacy of serious games in interventions for depression $[169,165]$, anxiety [176], and positive physical health outcomes in rehabilitation [175,177]. Additionally, a series of meta-analyses across these areas focus on the ability to draw conclusions regarding game efficacy $[178,179]$

A propensity for adopting randomised controlled trials does not mean that healthcare is not subject to the same evaluation methodological draw-backs demonstrated in other contexts. For instance, these studies often have small sample-sizes, do not take into account cultural or other demographical differences, and are undertaken over a short period [180,181,182]. Furthermore, several meta-analyses demonstrated a range of mostly positive results in regards to efficacy in the fields of exercise [183], promoting healthy lifestyles [184], and diabetes self-management [185]. Therefore, we can see the same challenges in healthcare that are apparent in educational and other contexts within this chapter- satisfactorily proving the efficacy of an amorphous medium across multiple use-cases.

\section{Conclusion}

This chapter has highlighted not only contextual commonalities, but also the diffusion and fluidity of the serious games ecosystem. It is now worth considering: what does this mean for the researcher? As a researcher you are likely to come across comparable justifications for serious games adoption, specifically through notions of 'engagement', 'motivation', or 'cost-effectiveness'. However, the actual effectiveness of these serious game interventions is currently a contentious is sue due to the contextual specificity of measurements, and frequently inadequate research protocols. In addition to this difficulty of evaluation, due to the multifaceted purposing of serious games, is the problem of inconsistent conceptualisation.

Games, in themselves, are a broad media capturing multiple instantiations of aesthetic, ludic, and narrative elements. Furthermore, serious games have a significant overlap with other fields such as simulation-based learning or gamification such that these terms are often conflated. Adding to this taxonomical confusion is the inconsistent use of the term 'serious games' itself. As repeatedly touched upon in this chapter there are several examples directly conflating 'serious games' - an umbrella term - with 'games-based learning', without making a distinction. Furthermore, there are multiple emerging, adjacent, umbrella terms used in place of 'serious games' such as 'applied games', 'purposed games', or 'procedural rhetoric'.

The sub-categories that exist within these umbrella terms of 'serious games' are themselves, again, a contentious field. 'Digital games-based learning' is used alongside 'educational games', or 'playful learning' and - occasionally - terminology such as an 'edutainment' that is used more prominently in other, non-games, fields, extending the intercontextual blur to an intermedia one. Reflecting this 'serious games' identity cris is is the changing role of serious games research as a contextually sensitive interdisciplinary field, meaning it is unlikely to be undertaken in a purely academic vacuum. 
Increasingly, inter-contextual serious games practice blurs the line between serious games academic research, commercial development, and contextual adoption. It is necessary to be contextually sensitive, as context will often dictate motivations and practices surrounding adoption, the theories and frameworks underlying the serious game's design, as well as the ways in which its efficacy is measured. These contexts are in a constant conversation with each other- fluidly overlapping but with a strong commercial driving force - as industry developmental trends shift. Additionally, these individual fields are in a constant state of flux themselves.

Some resources exist to smooth these transitions and connect these entities, like the RAGE project, which aims to "develop, transform and enrich advanced technologies from the leisure games industry into self-contained gaming as sets (i.e. solutions showing economic value potential) that support game studios at developing applied games, and make these assets available along with a large volume of high quality knowledge resources through a self-sustainable Ecosystem, which is a social space that connects research, gaming industries, intermediaries, education providers, policy makers and end-users." [186]

The contextual application of serious games is influenced by social, cultural, and political factors - from the perception of video games, to systematic frameworks governing effectiveness, to the access to, and familiarity with, technologies. In addition to the context specific fluctuations there also exist socio-cultural and technological factors that impact all contexts. For instance, governmental polices mandating national education frameworks will, to a degree, impact research directions, commercial development, and adoption of educational games. In addition, perhaps most obviously, but not yet acknowledged, is the development and access to technology itself.

In the last 10 years we have seen a trend of mobile devices gaining popularity as the preferred gaming platform of individuals [187], particularly amongst under-18s [188], and all roads point towards this trend continuing. Despite this, games for learning academic research projects are predominantly built for the PC platform, and other serious games areas seem to follow suit [73]. This illuminates a key-part of one of the main tensions of conducting research in this area - the different expectations of time-frames. It can be argued that academia is cursed to be playing perpetual catch-up with the adoption and development of serious games. The technological, commercial, and contextual specific factors create an action-orientated approach that isn't easily mapped on to the fastidious, reflective, and rigorous approach of academia.

The researcher can therefore consider themselves a facilitator of praxis, as researchers are frequently positioned at the intersection of theory and practice. For instance, there is renewed interest in participatory research methods - that value and empower research participants and context practitioners to become a part of the research and development process [189]. In addition, the research studies mentioned throughout this chapter, even if not explicitly linked, have reflected the research practices of actionoriented, practice-based, and practice-led research. Revisiting Eraut's pivotal quote from the beginning of this chapter highlights an ontological shift on the part of the researcher: 
"[Academia must] extend to its role from that of creator and transmitter of generalizable knowledge to that of 'enhancing knowledge creation capacities' of individuals and professional communities." [36]

This notion of praxis, when applied to serious games, attempts to capture the processes by which the relevant theories of academic, industry, and adoptive contexts come together to inform the contexts relative practices. These processes are multifaceted, depending on the adoptive contexts and academic disciplines involved, however their goal is the same -to generate impactful research. Given a shifting socio-political landscape, higher education research is frequently evaluated in terms of its impact [190].

For instance, at $€ 80$ billion, Horizon 2020 the largest EU research and innovation programme ever [191]. Horizon 2020 has two streams directly relevant to research into serious games - ICT 20: Technologies for better human learning and teaching and ICT 21: Advanced digitalgaming/gamification technologies - and as a programme has made "marks a shift towards the use of indicators that aim to capture results and impacts" [192].

Therefore, to undertake impactful research that has "an effect on, change or benefit to the economy, society, culture, public policy or services, health, the environment or quality of life, beyond academia" [193] requires an appreciation and sensitivity to both the interdisciplinary and intercontextual nature of the serious games ecosystem.

\section{References}

1. Bogost, I.: Persuasive Games: The Expressive Power of Videogames. MIT Press, Cambridge (2007)

2. Abt, C.: Serious Games. Abt Associates, Inc., New York City (1970)

3. Coventry University: About Serious Games Institute, http://www. coventry.ac.uk/events/games-for-heal th-uk-conference-2016/aboutserious-games-institute/

4. European Union Digital Library: EAI Endorsed Transactions on Serious Games, http://www.eudl.eu/issue/sg/1/1

5. Flanagan, M.: Critical Play: Radical Game Design. MIT Press, Massachusetts (2009)

6. Gee, J.: What Video Games Have to Teach Us About Learning and Literacy 2nd edn. Palgrave Macmillan, London (2007)

7. van Staalduinen, J.-P., de Freitas, S.: A Game-Based Learning Framework: Linking Game Design and Learning Outcomes. In: Learning to Play: Exploring the Future of Education with Video Games. pp. 29-55. Peter Lang, Bern (2011)

8. Djaouti, D., Alvarez, J., Jessel, J.-P.: Classifying Serious Games: The G/P/S Model. In: Handbook of Research on Improving Learning and Motivation through Educational Games: Multidisciplinary Approaches. pp. 118-136. IGI Global, Hershey (2011)

9. Rooney, P.: A Theoretical Framework for Serious Game Design: Exploring Pedagogy, Play and Fidelity and their Implications for the Design Process. Int. J. Game-Based Learn. 2(4), 41-60 (2012)

10. Rego, P., Moreira, P., Reis, L.: A Serious Games Framework for Health Rehabilitation. Int. J. Health. Info. Syst. Informa. 9(3), 1-21 (2014)

11. Horne-Moyer, H., Moyer, B., Messer, D., Messer, E.: The Use of Electronic Games in Therapy: A Review with Clinical Implications. Cur. Psych. Rep. 16(12), 1-9 (2014) 
12. Arnab, Lim, T., Carvalho, M., De Gloria, A.: Mapping learning and game mechanics for serious games analy sis. Brit. J. Edu. Tech. 46(2), 391-411 (2015)

13. Wartena, B., Kuipers, D., van Dijk, H.: Ludo Modi Varietas: A Game-architecture inspired design approach for BCSS. In: Öörni, A., Kelders, S., van Gemert-Pijnen, L., Oinas-Kukkonen, H., (eds.) Proceedings of the Second International Workshop on Behavior Change Support Sy stems (BCSS '14), Padua, Italy, pp.77-84. CEUR (2014)

14. Wilkinson, P.: Affective educational games: Utilizing emotions in game-based learning. In: 2013 5th International Conference on Games and Virtual Worlds for Serious Applications (VS-GAMES ‘13), Bournemouth, pp.1-8. IEEE (2013)

15. O'Neil, O., Gatzidis, C., Swain, I.: A State of the Art Survey in the Use of Video Games for Upper Limb Stroke Rehabilitation. In: Virtual, Augmented Reality and Serious Games for Healthcare 1.pp. 345-370. Springer, Heidelberg (2014)

16. Wu, W.-H., Hsaio, H.-C., Wu, P.-L., Lin, C.-H., Huang, S.-H.: Investigating the learningtheory foundations of game-based learning: A meta-analy sis. J. Comp. Assist. Learn. 28(3), 265-279 (2012)

17. Ratan, R., Ritterfeld, U.: Classify ing Serious Games. In: Serious Games: Mechanisms and Effects. pp. 10-24. Routledge, London (2009)

18. Sitzmann, T.: A Meta-Analy tic Examination of the Instructional Effectiveness of ComputerBased Simulation Games. Pers. Psych. 64(2), 489-528 (2011)

19. Wouters, P., van Nimwegen, C., van Oostendorp, H., van der Spek, E.: A meta-analy sis of the cognitive and motivational effects of serious games. J. Edu. Psych. 105(2), 249-265 (2013)

20. Ke, F.: A Qualitative Meta-Analy sis of Computer Games as Learning Tools. In: Handbook of Research on Effective Electronic Gaming in Education 1. pp. 1-32. IGI Global, Hershey, Pennsylvania (2008)

21. All, A., Castellar, E., van Looy, J.: Measuring effectiveness in digital game-based learning: a methodological review. Int. J. Serious Gam. 2(1), 3-20 (2014)

22. All, A., Castellar, E., van Looy, J.: Assessing the effectiveness of digital game-based learning: Best practices. Comp. \& Edu. 92(C), 90-103 (2016)

23. All, A., Castellar, E., van Looy, J.: Defining effectiveness of digital game-based learning: a socio-cognitive approach. In: Busch, C., (ed.) Proceedings of the 8th European Conference On Games Based Learning (ECGBL 2014), Berlin, Germany, pp. 669-675. Academic Conferences and Publishing (2014)

24. Stokes, B., O'Shea, G., Walden, N., Nasso, F., Mariutto, G., Hill, A., Burak, A.: Impact with Games: A Fragmented Field. Report, Games for Change (2016)

25. Connolly, T., Boyle, E., MacArthur, E., Hainey, T., Boyle, J.: A systematic review of empirical evidence on computer games and serious games. Comp. \& Edu. 59(2), 661-686 (2012)

26. Yusoff, A., Crowder, R., Gilbert, L.: Validation of Serious Games Attributes Using the Technology Acceptance Model. In: Debattista, K., Dickey, M., Proença, A., Santos, L., (eds.) 2010 Second International Conference on Games and Virtual Worlds for Serious Applications (VS-GAMES), Braga, pp.45-51. IEEE (2010)

27. Rao, V.: A Framework for Evaluating Behavior Change Interventions through Gaming. In: Reidsma, D., Haruhiro, K., Nijholt, A., (eds.) ACE 2013. LNCS, 8253, pp.368-379. Springer, Heidelberg (2013)

28. Desurvire, H., Wiberg, C.: Game Usability Heuristics (PLAY) for Evaluating and Designing Better Games: The Next Iteration. In: Ozok, A., Zaphiris, P., (eds.) OCSC 2009. LNCS, 5621, pp.557-566. Springer, Heidelberg (2009) 
29. Jerzak, N., Rebelo, F.: Serious Games and Heuristic Evaluation - The Cross-Comparison of Existing Heuristic Evaluation Methods for Games. In: Marcus, A., (ed.) DUXU 2014. LNCS, 8517, pp.453-464. Springer, Heidelberg (2014)

30. Steiner, C., Nussbaumer, A., Kluijhout, E., Nadolski, R., Bazzanella, B., Mscarenhas, S., Ger, P., Dascalu, M., Trausan-Matu, S., Becker, J., Yuan, L., Hollins, P.: RAGE Evaluation Framework and Guidelines. Project Deliverable, Graz University of Technology, (2016)

31. Arnab, S., Riccardo, B., Earp, J., de Freitas, S., Popescu, M., Romero, M., Stanescu, I., Usart, M.: Framing the Adoption of Serious Games in Formal Education. E-J. E-Learn. 10(2), 159171 (2012)

32. Arnab, S., de Freitas, S., Bellotti, F., Lim, T., Louchart, S., Suttie, N., Berta, R., de Gloria, A.: Pedagogy-driven design of Serious Games: An overall view on learning and game mechanics mapping, and cognition-based models. Research Report, Serious Games Institute (2012)

33. Ulicsak, M., Williamson, B.: Computer games and learning. Futurelab, London (2011)

34. Azadegan, A., Riedel, J., Hauge, J.: Serious Games Adoption in Corporate Training. In: Ma, M., Oliveira, M., Hauge, J., Duin, H., Thoben, K.-D., (eds.) SGDA 2012. LNCS, 7528, pp.74-85. Springer, Heidelberg (2012)

35. Watt, J.: Improving Methodology in Serious Games Research with Elaborated Theory. In: Serious Games: Mechanisms and Effects. pp. 374-388. Routledge, London (2009)

36. Eraut, M.: Developing professional knowledge and competence. Routledge, London (1994)

37. Jencks, C., Riesman, D.: The Academic Revolution. Doubleday, New York (1968)

38. Etzkowitz, H.: The norms of entrepreneurial science: cognitive effects of the new universityindustry linkages. Res. Pol. 27(8), 823-833 (1998)

39. Etzkowitz, H., Webster, A., Gebhardt, C., Terra, B.: The future of the university and the university of the future: evolution of ivory tower to entrepreneurial paradigm. Res. Pol. 29(2), 313-330 (2000)

40. Bellotti, F., Berta, R., De Gloria, A.: Games and Learning Alliance (GaLA) SupportingEducation and Training through Hi-Tech Gaming. In: 12th International Conference on Advanced Learning Technologies, Rome, pp.740-741. IEEE (2012)

41. Serious Games Institute: SGI Community, http://www.seriousgamesinstitute.co.uk/community/

42. Serious Game Society: About, http://www.seriousgamessociety.org/index.php/joomla-pages/about-us

43. Etzkowitz, H.: Research groups as 'quasi-firms': the invention of the entrepreneurial university. Res. Pol. 32(1), 109-121 (2003)

44. Riestra, R., Westera, W.: The RAGE project aims at boosting games development for education and training in Europe. Press Release, Hull College (2015)

45. de Freitas, S., Mayer, I., Arban, S., Marshall, I.: Industrial and academic collaboration: hybrid models for research and innovation diffusion. J. High. Edu. Pol. Manage. 36(1), 2-14 (2014)

46. Serious Games International: About us, http://www.seriousgamesinternational. com/about-us/

47. PlayGen: About PlayGen, http://playgen.com/company_index/

48. PlayGen: FloodSim, http://playgen.com/play/floodsim/

49. PlayGen: Choices \& Voices, http://playgen.com/play/choices-andvoices/

50. IBM Corporation: Serious Solutions with Serious Games. Whitepaper, IBM Global Services (2011)

51. Deloitte: Serious Games, http://deloitte-learning.com/ ?page_id=4 38 
52. Adkins, S.: The 2014-2019 Global Edugame Market. Whitepaper, Ambient Insight (2015)

53. Cai, M.: Serious Games, Serious Play. Presentation, Interpret (2012)

54. Adkins, S.: The 2012-2017 Worldwide Game-based Learning and Simulation-based Markets. Presentation, Ambient Insight (2012)

55. Marketsandmarkets: Serious Game Market by Vertical (Education, Corporate, Healthcare, Retail, Media and Advertising), Application (Training, Sales, Human Resource, Marketing), Platform, End-User (Enterprise, Consumer), and Region - Forecast to 2020. Market Research, Marketsandmarkets (2015)

56. Games for Change: About, http://www.gamesforchange.org/about/

57. Swain, C.: Designing Games to Affect Social Change. In: Baba, A., (ed.) Proceedings of the 2007 DiGRA International Conference (DiGRA '07), Tokyo. JAPAX (2007)

58. Games for Change: G4C13 Sex Etc. Game Design Competition, http: / / www. gamesforchange. org/learn/g4c13-sex-etc-game-design-competition-results/

59. Games for Change: N Square Challenge $\$ 10,000$ Game Design Competition Around Nuclear Weapons, http: //www.gamesforchange. org/2015/10/n-s qua re game-design-challenge/

60. Reckian, D., Eisenack, K.: Climate Change: Gaming on Board and Screen. Sim. \& Gam. 44(2-3), 253-271 (2013)

61. Arora, P., Itu, S.: Arm chair activism: Serious games usage by INGOs for educational change. Int. J. Game-Based Learn. 2(4), 1-17 (2012)

62. Pereira, G., Brisson, A., Prada, R., Paiva, A., Bellotti, F., Kravcik, M., Klamma, R.: Serious Games for Personal and Social Learning \& Ethics: Status and Trends. In: de Gloria, A., de Freitas, S., (eds.) 4th International Conference on Games and Virtual Worlds for Serious Applications (VS-GAMES'12), Genoa, pp. 53-65. Elsevier Procedia (2012)

63. Quinn, Z.: Depression Quest An Interaction (non)Fiction About Living With Depression, http: //www. depressionquest.com/

64. Numinous Games: That Dragon Cancer, http: //www. thatdragoncancer. com/

65. Sinclair, B.: Serious games stigmatized in and out of the industry, says Schell, http://www.gamesindustry.biz/articles/2013-05-30-seriousgames-stigmatized-in-and-out-of-the-industry-says-schell

66. Saveski, G., Westera, W., Yuan, L., Hollins, P., Manjón, B., Ger, P., Stefanov, K.: What Serious Game Studios Want from ICT Research: Identify ing Developers' Needs. In: de Gloria, A., Veltkamp, R., (eds.) GALA 2015, LNCS, 9599, pp.32-41. Springer, Heidelberg (2015)

67. PlayGen: MeTycoon, http://playgen.com/play/me-tycoon/

68. Skinner, B.: The Technology of Teaching. Meridith Corporation (1968)

69. Dunwell, I., Lameras, P., de Freitas, S., Petridis, P., Star, K., Hendrix, M., Arnab, S.: MeTycoon: A game-based approach to career guidance. In: 5th International Conference on Games and Virtual Worlds for Serious Applications (VS-GAMES'13), Bournemouth, pp.16. IEEE (2013)

70. BECTA: Engagement and motivation in games development processes. Research Report, BECTA (2006)

71. Culyba, S.: Report response Sabrina of Schell Games. http://gameimpact. net/response-culyba-schell/

72. Bachvarova, Y., Bocconi, S., van der Pols, B., Popescu, M., Roceanu, I.: Measuring the Effectiveness of Learning with Serious Games in Corporate Training. In: de Gloria, A., de Freitas, S., (eds.) 4th International Conference on Games and Virtual Worlds for Serious Applications (VS-GAMES '12), Genoa, pp.221-232. Elsevier (2012) 
73. Cheng, M.-T., Chen, J.-H., Chu, S.-J., Chen, S.-Y.: The use of serious games in science education: a review of selected empirical research from 2002 to 2013. J. Comp. Edu. 2(3), 353-375 (2015)

74. REF: About the REF. http: / / www .ref.ac.uk/about/

75. Klimmt, C.: Serious games for social change: Why they (should) work. In: Serious Games: Mechanisms and Effects. pp. 248-270. Routledge, London (2009)

76. Turkle, S.: The Second Self. Simon \& Schuster, New York (1984)

77. Csikszentmihalyi, M.: Flow: The Psy chology of Optimal Experience. Harper \& Row, New York (1990)

78. Iacovides, I., Aczel, J., Scanlon, E., Taylor, J., Woods, W.: Motivation, engagement and learning through digital games. Int. J. Virt. Pers. Learn. Environ. 2(2), 1-16 (2011)

79. Kiili, K., de Freitas, S., Arnad, S., Lainema, T.: The Design Principles for Flow Experience in Educational Games. In: de Gloria, A., de Freitas, S., (eds.) 4th International Conference on Games and Virtual Worlds for Serious Applications (VS-GAMES '12), Genoa, pp.7891. Elsevier (2012)

80. Kiili, K., Perttula, A., Arnab, S., Suominen, M.: Flow Experience as a Quality Measure in Evaluating Physically Activating Serious Games. In: de Gloria, A., (ed.) GALA 2013. LNCS, 8605, pp.200-212. Springer, Heidelberg (2014)

81. Bellotti, F., Kapralos, B., Lee, K., Moreno-Ger, P., Berta, R.: Assessment in and of Serious Games: An Overview. Adv. HCI 2013, 1-11 (2013)

82. Terlutter, R., Capella, M.: The Gamification of Advertising: Analysis and Research Directions of In-Game Advertising, Advergames, and Advertising in Social Network Games. J. Advert. 42(2-3), 95-112 (2013)

83. Nelson, M.: Exploring consumer response to "advergaming". In: Online Consumer Psychology: Understanding and Influencing Consumer Behavior in the Virtual World. pp. 156-182. Lawrence Erlbaum Associates, New Jersey (2005)

84. Chipotle: The Scarecrow, http: //www. scarecrowgame. com/game.html

85. Weed, A.: Engaging consumers with advergames: Case study of Chipotle's "The Scarecrow". Conference Presentation, MBAA (2015)

86. Harris, J., Speers, S., Schwartz, M., Brownell, K.: US Food Company Branded Advergames on the Internet: Children's exposure and effects on snack consumption. J. Child. Med. 6(1), 51-68 (2012)

87. World Food Programme: About,http://freerice.com/about

88. Mariana, C.: Freerice.com - Free Education Based on AppealingLevel-Based English Tests. In: Roceanu, I., (ed.) Proceedings of the 8th International Scientific Conference "eLearning and Software for Education", Bucharest, p.6. Editura Universitara (2012)

89. Zynga: Give the gift of play this holiday season. https://blog.zynga.com/2012/11/28/toys-for-tots/

90. Birkwood, S.: Video game industry 'could be a goldmine for charity fundraisers'. http://www.thirdsector.co.uk/video-game-industry-couldgoldmine-charity-fundraisers/fundraising/article/1347151

91. Cancer Research UK: Citizen Science. http://www. cancerresearchuk.org/support-us/citizen-science

92. Center for Game Science at University of Washington: The Science Behind Foldit, http://fold.it/portal/info/about

93. America's Army: America's Army Backgrounder. Press Release, United State's Army (2013)

94. Nieborg, D.: America's Army: more than a game? In: Eberle, T., Kriz, W., (eds.) 35th Annual Conference of the International Simulation and Gaming Association (ISAGA '04), Munich, p.2. SAGSAGA (2004) 
95. Galloway, A.: Social Realism in Gaming. Int. J. Comp. Gam. Res. 4(1) (2004)

96. American Civil Liberties Union: Soldiers of Misfortunate: Abusive U.S. Military Recruitment and Failure to Protect Child Soldiers. Report, American Civil Liberties Union (2008)

97. Wardynski, E.: Informing Popular Culture: The America's Army Game Concept. In: America's Army PC Game Vision and Realization. pp. 6-8. The Wecker Group, Monterey (2004)

98. Smith, R.: The Long History of Gaming in Military Training. Simul. Gam. 41(1), 6-19 (2010)

99. Haworth, R., Sedig, K.: The importance of design for educational games. In: Education in a technological world: communicating current and emerging research and technological efforts. pp. 518-522. Formatex, Badajoz (2011)

100. Squire, K., Jenkins, H.: Harnessing the power of games in education. Insight. 3(1), 5-33 (2003)

101. Riedel, J., Feng, Y., Azadegan, A., Romero, M., Usart, M., Hauge, J.: Measuring the Commercial Outcomes of Serious Games in Companies - A Review. In: Ma, M., Oliveira, M., Hauge, J., (eds.) SGDA 2014. LNCS, 8778, pp.176-191. Springer, Heidelberg (2014)

102. Johnson, W., Wu, S.: Assessing Aptitude for Learning with a Serious Game for Foreign Language and Culture. In: Woolf, B., Aïmeur, E., Nkambou, R., Lajoie, S., (eds.) ITS 2008. LNCS, 5091, pp.520-529. Springer, Heidelberg (2008)

103. O'Neil, H., Wainess, R., Baker, E.: Classification of learning outcomes: evidence from the computer games literature. Curricul. J. 16(4), 455-474 (2005)

104. Martínez-Durá, R., Arevalillo-Herráez, M., García-Fernández, I., Gamón-Giménez, M., Rodríguez-Cerro, A.: Serious Games for Health and Safety Training. In: Serious Games and Edutainment Applications. pp. 107-124. Springer, London (2011)

105. Kirkpatrick, D.: Techniques for evaluating training programs. Train. Dev. J. 33(1), 78-92 (1979)

106. Donovan, L.: The Use of Serious Games in the Corporate Sector. Report, Learnovate Centre (2012)

107. Bloom, B.: Learning for Mastery. Eval. Comment. 1(2), 1-12 (1968)

108. Hays, M., Ogan, A., Lane, H.: The Evolution of Assessment: Learning about Culture from a Serious Game. In: Lynch, C., Ashley, K., Mitrovic, T., Dimitrova, V., Pinkwart, N., Aleven, V., (eds.) ITS 2010. LNCS, 6094, pp.37-44. Springer, Heidelberg (2010)

109. Williamson, B.: Computer games, schools, and young people: A report for educators on using games for learning. Research Report, Futurelab (2009)

110. Internet Advertising Bureau UK: Gaming Revolution. Research Report, Internet Advertising Bureau UK (2014)

111. Buckingham, D.: Is There A Digital Generation? In: Digital Generations: Children, Young People, and the New Media. pp. 1-18. Lawrence Erlbaum Associates, New Jersey (2006)

112. Prensky, M.: Digital Game-Based Learning. McGraw-Hill Education, New York (2001)

113. de Freitas, S., Rebolledo-Mendez, G., Liarokapis, F., Magoulas, G., Poulovassilis, A.: Learning as immersive experiences: Using the four-dimensional framework for designing and evaluating immersive learning experiences in a virtual world. Brit. J. Edu. Tech. 41(1), 69-85 (2010)

114. Sandford, R., Facer, K., Williamson, B.: Constructions of games, teachers and young people in formal learning. In: Digital Games and Learning. pp. 175-199. Continuum, New York (2011)

115. Sandford, R., Ulicsak, M., Facer, K., Rudd, T.: Teaching with Games: Using commercial off-the-shelf computer games in formal education. Research Report, Futurelab (2006)

116. Sandford, R., Williamson, B.: Games and Learning: A Handbook. Futurelab, Bristol (2005) 
117. Berger, R., McDougall, J.: Reading videogames as (authorless) literature. Lit. 47(3), 142149 (2013)

118. Baek, Y.: What Hinders Teachers in Using Computer and Video Games in the Classroom? Exploring Factors Inhibiting the Uptake of Computer and Video Games. CyberPsych. Behav. 11(6), 665-671 (2008)

119. Oxford University Press: MyMaths - Bringing maths alive. https://www.mymaths.co.uk/index.html

120. Lexia Learn: Why Lexia. http://www.lexialearning.com/why-lexia

121. Loh, C., Sheng, Y., Ifenthaler, D.: Serious Games Analytics: Methodologies for Performance Measurement, Assessment, and Improvement. Springer International, Switzerland (2015)

122. Takeuchi, L., Stevens, R.: The New Coviewing: Designing for Learning through Joint Media Engagement. Research Report, The Joan Ganz Cooney Center (2011)

123. Rideout, V.: Learning at Home: Families' Educational Media Use in America. Research Report, The Joan Ganz Cooney Center (2014)

124. Sesame Workshop: workshop at a glance. http://www. sesameworkshop.org/about-us/workshop-at-a-glance/

125. Vygotsky, L.: Mind in Society: Development of Higher Psychological Processes. Harvard University Press, Cambridge (1978)

126. Egenfeldt-Nielson, S.: Third Generation Educational Use of Computer Games. J. Edu. Med. Hypermed. 16(3), 263-281 (2007)

127. Driscoll, M.: Psychology of Learning for Instruction. Allyn and Bacon, Boston (1994)

128. Papert, S.: Does Easy Do It? Children, Games, and Learning. Article, Game Developer Magazine (1998)

129. Peppler, K., Kafai, Y.: From SuperGoo to Scratch: exploring creative digital media production in informal learning. Learn. Med. Tech. 32(2), 149-166 (2007)

130. Kafai, Y., Burke, Q.: Connected Code: Why Children Need to Learn Programming. MIT Press, Cambridge (2014)

131. Papert, S.: Mindstorms: children, computers, and powerful ideas. Basic Books, New York (1980)

132. Kafai, Y.: The classroom as living laboratory: design-based research for understanding, comparing, and evaluating learning science through design. Edu. Tech. 45(1), 28-34 (2005)

133. Marchiori, E., Torrente, J., del Blanco, Á., Moreno-Ger, P., Sancho, P., Fernández-Manjón, B.: A narrative metaphor to facilitate educational game authoring. Comp. Edu. 58(1), 590599 (2012)

134. Robertson, J., Howells, C.: Computer game design: Opportunities for successful learning. Comp.Edu. 50(2), pp.559-578 (2008)

135. Li, Q., Vandermeiden, E., Lemieux, C., Nathoo, S.: Secondary students learning mathematics through digital game building: A study of the effects and students' perceptions. Int. J. Tech. Math. Edu. 23(1), 25-34 (2016)

136. Microsoft: What is Kodu? http://www. kodugamelab.com/about/

137. Microsoft: About Imagine Cup. https://www. imaginecup. com/cust om/About

138. The Joan Ganz Cooney Center: National STEM Video Game Challenge. http://www.joanganzcooneycenter.org/initiative/stemchallenge/

139. Baranowski, T., Blumberg, F., Buday, R., DeSmet, A., Fiellin, L., Green, C., Kato, P., Lu, A., Maloney, A., Mellecker, R., Morrill, B., Peng, W., Shegog, R., Simons, M., Staiano, A., Thompson, D., Young, K.: Games for Health for Children - Current Status and Needed Research. Gam. Health J. 5(1), 1-12 (2016) 
140. Graafland, M., Schraagen, J., Schijven, M.: Sy stematic review of serious games for medical education and surgical skills training. Brit. J. Surg. 99(10), 1322-1330 (2012)

141. de Paolis, L., Ricciardi, F., Giuliani, F.: Development of a Serious Game for Laparoscopic Suture Training. In: De Paolis, L., Mongelli, A., (eds.) AVR 2014. LNCS, 8853, pp.90-102. Springer, Heidelberg (2014)

142. Sabri, H., Cowan, B., Kapralos, B., Porte, M., Backstein, D., Dubrowskie, A.: Serious games for knee replacement surgery procedure education and training. Soc. Behav. Sci. 2(2), 34833488 (2010)

143. Park, S., Yoon, Y., Kim, L., Lee, S.: Virtual knee joint replacement surgery system. In: Geometric Modeling and Imaging (GM AI '07), Zurich, pp.79-84. IEEE (2007)

144. Qin, J., Chui, Y.-P., Pang, W.-M., Choi, K.-S., Heng, P.-A.: Learning Blood Management in Orthopedic Surgery through Gameplay. Comp. Graph. Appl. 30(2), 45-57 (2009)

145. Parsons, G., Richards, B.: Virtual Pain Manager. http: //vpm.glam.ac.uk/

146. Santé Training: Florence: Blood Transfusion. http://www. sante-training.com/cata logue/19-serious-games/8-serious-game-transfusion-sanguine

147. Ricciardi, F., De Paolis, L.: A Comprehensive Review of Serious Games in Health Professions. Int. J. Comp. Gam. Tech., 11(9), 1-11 (2014)

148. BreakAway Games: Code Orange. http://www.breakawaygames.com/games/code-orange/

149. Lieberman, D.: Video games for diabetes self-management: examples and design strategies. J. Diab. Sci. Tech. 6(4), 802-806 (2012)

150. Nobel Media AB: Diabetes and Insulin. https://www. nobelprize.org/educational/medicine/insulin/index.html

151. Lieberman, D.: Digital games for health behavior change: Research, design, and future directions. In: eHealth Applications: Promising Strategies for Behavior Change. pp. 110-127. Routledge, London (2012)

152. DeShazo, J., Harris, L., Pratt, W.: Effective Intervention or Child's Play? A Review of Video Games for Diabetes Education. Diab. Tech. Thera. 12(10), 815-822 (2010)

153. Klingensmith, G., Aisenberg, J., Kaufman, F., Halvorson, M., Cruz, E., Riordan, M., Varma, C., Pardo, S., Viggiani, M., Wallace, J., Schandner, H., Bailey, T.: Evaluation of a combined blood glucose monitoring and gaming system (Didget $\left.{ }^{\circledR}\right)$ for motivation in children, adolescents, and young adults with type 1 diabetes. Ped. Diab. 14(5), 350-357 (2013)

154. Bandura, A.: Social Foundations of Thought and Action: A Social Cognitive Theory. Pearson, London (1986)

155. Thompson, D.: Designing Serious Video Games for Health Behavior Change: Current Status and Future Directions. J. Diab. Sci. Tech. 6(4), 807-811 (2012)

156. Tate, R., Haritatos, J., Cole, S.: HopeLab's Approach to Re-Mission. Int. J. Learn. Med. 1(1), 29-35 (2009)

157. Govender, M., Bowen, R., German, M., Bulaj, G., Bruggers, C.: Clinical and Neurobiological Perspectives of Empowering Pediatric Cancer Patients Using Videogames. Gam. Health J. 4(5), 362-374 (2015)

158. Merry, S., Stasiak, K., Shepard, M., Frampton, C., Fleming, T., Lucassen, M.: The effectiveness of SPARX, a computerised self help intervention for adolescents seeking help for depression: randomised controlled non-inferiority trial. Brit. Med. J. 344(7857), 16 (2012)

159. Bruce, V., Kutcher, S.: Electronic interventions for depression in adolescents: hot idea or hot air? S. Africa. J. Psych., 1(1) 1-13 (2016) 
160. Inglés-Camats, G., Presno-Rivas, M., Antonijoan, M., Garcia-Panella, O., Forrest, T.: Yummy tricks: a serious game for learning healthy eating habits. Stud. Health Tech. Inform. 172(1), 185-190 (2012)

161. Thompson, D., Bhatt, R., Lazarus, M., Cullen, K., Baranowski, J., Baranowski, T.: A Serious Video Game to Increase Fruit and Vegetable Consumption Among Elementary Aged Youth (Squire's Quest! II): Rationale, Design, and Methods. JMIR Res. Proto. 1(2), e19 (2012)

162. Baranowski, T., Buday, R., Thompson, D., Lyons, E., Lu, A., Baranowski, J.: Developing Games for Health Behavior Change: Getting Started. Gam. Health J. 2(4), 183-190 (2013)

163. Peng, W.: Design and Evaluation of a Computer Game to Promote a Healthy Diet for Young Adults Computer Game as a Medium for Health Promotion. Health Comm. 24(2), 115-127 (2009)

164. Rusch, D.: "Elude": designing depression. In: El-Nasr, M. S., Consalvo, M., Feiner, S., (eds.) Proceedings of the International Conference on the Foundations of Digital Games (FDG 2012), Raliegh, pp.254-257. ACM (2012)

165. Russoniello, C., Fish, M., O'Brien, K.: The Efficacy of Casual Videogame Play in Reducing Clinical Depression: A Randomized Controlled Study. Gam. Health J. 2(6), 341-346 (2013)

166. Fish, M., Russoniello, C., O'Brien, K.: The Efficacy of Prescribed Casual Videogame Play in Reducing Symptoms of Anxiety: A Randomized Controlled Study. Games. Health J. 3(5), 291-295 (2014)

167. Swanson, L., Whittinghill, D.: Intrinsic or Extrinsic? Using Videogames to Motivate Stroke Survivors: A Sy stematic Review. Gam. Health J. 4(3), 253-258 (2015)

168. Szturm, T., Reimer, K., Hochman, J.: Home-Based Computer Gaming in Vestibular Rehabilitation of Gaze and Balance Impairment. Gam. Health J. 4(3), 211-220 (2015)

169. Roepke, A., Jaffee, S., Riffle, O., McGonigal, J., Broome, R., Maxwell, B.: Randomized Controlled Trial of SuperBetter, a Smartphone-Based/Internet-Based Self-Help Tool to Reduce Depressive Sy mptoms. Gam. Health J. 4(3), 235-246 (2015)

170. Larsen, L., Schou, L., Lund, H., Langberg, H.: The Phy sical Effect of Exergames in Healthy Elderly -A Sy stematic Review. Gam. Health J. 2(4), 205-212 (2013)

171. Hall, A., Chavarria, E., Maneeratana, V., Chaney, B., Bernhardt, J.: Health Benefits of Digital Videogames for Older Adults: A Systematic Review of the Literature. Gam. Health J. 1(6), 402-410 (2012)

172. McCallum, S., Boletsis, C.: Dementia Games: A Literature Review of Dementia-Related Serious Games. In: Ma, M., Oliveira, M., Petersen, S., Hauge, J., (eds.) SGDA 2013. LNCS, 8101, pp.15-27. Springer, Heidelberg (2013)

173. Robert, P., König, A., Amieva, H., Andrieu, S., Bremond, F., Bullock, R., Ceccaldi, M., Dubois, B., Gauthier, S., Kenigsberg, A., Nave, S., Orgogozo, J., Piano, J., Benoit, M., Touchon, J., Vellas, B., Yesavage, J., Manera, V.: Recommendations for the use of Serious Games in people with Alzheimer's Disease, related disorders and frailty. Front. Aging Neurosci. 6, 54 (2014)

174. Burns, M., Andeway, K., Eppenstein, P., Ruroede, K.: Use of the Wii Gaming System for Balance Rehabilitation: Establishing Parameters for Healthy Individuals. Gam. Health J. 3(3), 179-183 (2014)

175. Sato, K., Kuroki, K., Saiki, S., Nagatomi, R.: Improving Walking, Muscle Strength, and Balance in the Elderly with an Exergame Using Kinect: A Randomized Controlled Trial. Gam. Health J. 4(3), 161-167 (2015)

176. Pham, Q., Khatib, Y., Stansfeld, S., Fox, S., Green, T.: Feasibility and Efficacy of an mHealth Game for Managing Anxiety: "Flowy" Randomized Controlled Pilot Trial and Design Evaluation. Gam. Health J. 5(1), 50-67 (2016) 
177. Bower, K., Clark, R., McGinley, J., Martin, C., Miller, K.: Feasibility and Efficacy of the Nintendo Wii Gaming Sy stem to Improve Balance Performance Post-Stroke: Protocol of a Phase II Randomized Controlled Trial in an Inpatient Rehabilitation Setting. Gam. Health J. 2(2), 103-108 (2013)

178. Jinhui, L., Theng, Y.-L., Foo, S.: Game-Based Digital Interventions for Depression Therapy: A Systematic Review and Meta-Analysis. Cyberpsych. Beh. Soc. Net. 17(8), 519-527 (2014)

179. Theng, Y.-L., Lee, J., Patinadan, P., Foo, S.: The Use of Videogames, Gamification, and Virtual Environments in the Self-Management of Diabetes: A Systematic Review of Evidence. Gam. Health J. 4(5), 352-361 (2015)

180. Rahmani, E., Boren, S.: Videogames and Health Improvement: A Literature Review of Randomized Controlled Trials. Gam. Health J. 1(5), 331-341 (2012)

181. Kato, P.: Evaluating Efficacy and Validating Games for Health. Gam. Health J. 1(1), 74-76 (2012)

182. Kharrazi, H., Lu, A., Gharghabi, F., Coleman, W.: A Scoping Review of Health Game Research: Past, Present, and Future. Gam. Health J. 1(2), 153-164 (2012)

183. Gao, Z., Chen, S., Pasco, D., Pope, Z.: A meta-analysis of active video games on health outcomes among children and adolescents. Obes. Rev. 16(9), 783-794 (2015)

184. DeSmet, A., Ryckeghem, D., Compernolle, S., Baranowski, T., Thompson, D., Crombez, G., Poels, K., Van Lippevelde, W., Bastiaensens, S., Van Cleemput, K., Vandebosch, H., De Bourdeaudhuij, I.: A meta-analysis of serious digital games for healthy lifestyle promotion. Prev. Med. 69(1), 95-107 (2014)

185. Coyle, M., Francis, K., Chapman, Y.: Self-management activities in diabetes care: a systematic review. Austral. Health Rev. 37(4), 512-522 (2013)

186. Riestra, R., Urbina, M., Guaylupo, S., Westera, W., Star, K.: RAGE Dissemination Plan. Project Deliverable, INMARK (2015)

187. Entertainment Software Association: Essential Facts about the Computer and Video Game Industry. Market Research, Entertainment Software Association (2016)

188. NPD Group: Kids and Gaming 2015. Market Research, NPD Group (2015)

189. Khaled, R., Vasalou, A.: Bridging serious games and participatory design. Int. J. ChildComp. Inter. 2(2), 93-100 (2014)

190. Penfield, T., Baker, M., Scoble, R., Wykes, M.: Assessment, evaluations, and definitions of research impact: A review. Res. Eva. 23(1), 21-32 (2014)

191. European Commission: What is Horizon 2020? https://ec.europa.eu/programmes/horizon2020/en/what-horizon-2020

192. European Commission: Horizon 2020 indicators: Assessing the results and impact of Horizon 2020. Project Documentation, European Commission (2015)

193. Research Excellence Framework: Assessment framework and guidance on submissions. Documentation, Research Excellence Framework (2011)

194. Crookall, D.: Serious Games, Debriefing, and Simulation/Gaming as a Discipline. Sim. Gam. 41(6), 898-920 (2010) 